\title{
OBSERVING PLANKTONIC ECOSYSTEMS: NEEDS, CAPABILITIES, AND A STRATEGY FOR THE NEXT DECADE
}

\author{
Kenneth Denman $^{(1)}$, T. Malone ${ }^{(2)}$, S. Sathyendranath ${ }^{(3)}$,M.E. Sieracki ${ }^{(4)}$, E. Vanden Berghe $^{(5)}$ \\ ${ }^{(1)}$ Fisheries and Oceans Canada, Canadian Centre for Climate Modelling \& Analysis, clo University of \\ Victoria, PO Box 3065 STN CSC, Victoria BC V8W 3V6 Canada, Email: ken.denman@ec.gc.ca \\ ${ }^{(2)}$ Horn Point Laboratory, UMCES, 2020 Horn Point Road, Cambridge, MD 21613, USA, \\ Email: malone@umces.edu \\ (3) Plymouth Marine Laboratory, Prospect Place, West Hoe, Plymouth, PL1 3DH, UK, Email: ssat@pml.ac.uk \\ ${ }^{(4)}$ Bigelow Laboratory for Ocean Sciences, PO Box 475 West Boothbay Harbor, ME 04575, USA, \\ Email: msieracki@bigelow.org \\ ${ }^{(5)}$ Ocean Biogeographic Information System, Rutgers University, Institute of Marine and Coastal Sciences, \\ 71 Dudley Road, New Brunswick, NJ 08901,USA, Email: evberghe@iobis.org
}

\begin{abstract}
We review the current state of our capabilities for the systematic sustained observation of ocean ecosystems, concentrating primarily on planktonic ecosystems. First, we describe the structure of ocean ecosystems from the nutrients that support primary production, up through the plankton, and then through the various predators, from juvenile finfish to whales, sea lions and humans. We try to draw a picture of the ocean ecosystem (and related biogeochemical cycles) as complex, dynamic systems embedded in the equally complex and dynamic system represented by physical ocean processes. We describe the properties of ecosystems that biologists need to observe and understand, if they are to forecast the future behaviour of ocean ecosystems. Second, we identify the major users and uses for sustained observations of marine ecosystems. Third, we summarize how ocean ecosystems are observed from ships, trying to get across the need to describe the 'texture' as well as the dynamics of ocean ecosystems. Fourth, we review and present examples of the main components of emerging ecosystem observing systems. Finally, we discuss the gaps in existing capabilities and suggest a strategy to guide the development of sustained observations of planktonic ecosystems over the next decade.
\end{abstract}

\section{INTRODUCTION TO OCEAN ECOSYSTEMS}

There is wide acknowledgment that capabilities for systematic observation of ocean biogeochemistry and especially ocean ecosystems lag behind current capabilities and implementation of observing systems to observe the state of physical properties of the ocean. A planned outcome of OceanObs'09 is:

"A working group of limited duration and representing all participating groups should be established to recommend a way forward for the integration of additional needs of the marine ecosystem, biogeochemistry and fisheries communities in an enhanced sustained ocean observing system in the coming decade."

Thus, we need a strategy for developing and implementing over the next decade observing systems for ocean biogeochemistry and ecosystems integrated with current ocean observing systems.

In this paper, our primary goal is to present a status report of current observing capabilities for ocean ecosystems, as developed over the last decade. Others at this meeting have shown systems that are currently emerging, e.g. [1] and [2]. We take a two-pronged approach. First, we attempt to summarize current thinking on the structure and function of ocean ecosystems, from both foodweb and biogeochemical perspectives. We attempt to illustrate the complexity of ocean ecosystems and pose several questions to illustrate what qualities or properties of ocean ecosystems we need to observe and to understand if we are to attempt to predict their behaviour into a future that is being transformed by a variety of human activities. And second, we illustrate the nature of shipbased observations of ecosystems, emphasizing planktonic ecosystems that support marine food webs and fisheries, and that are responsible for cycling and transforming carbon in the oceans.

\subsection{Ocean Ecosystems Are Complex and Dynamic}

A major advance in the study of ocean ecosystems has been the development and launching of ocean color sensors on satellites, which estimate surface phytoplankton chlorophyll pigment concentration, and photosynthetic primary production. The SeaWiFS sensor mission has been providing global observations for over a decade - demonstrating both the great power of global data and the incredibly complex structures in phytoplankton populations and how they vary in time and space. However, from the schematic ocean ecosystem shown in Fig. 1, it is clear that phytoplankton are only the first level of ocean ecosystems. Most other components of ecosystems are not so amenable to space borne and global coverage. 


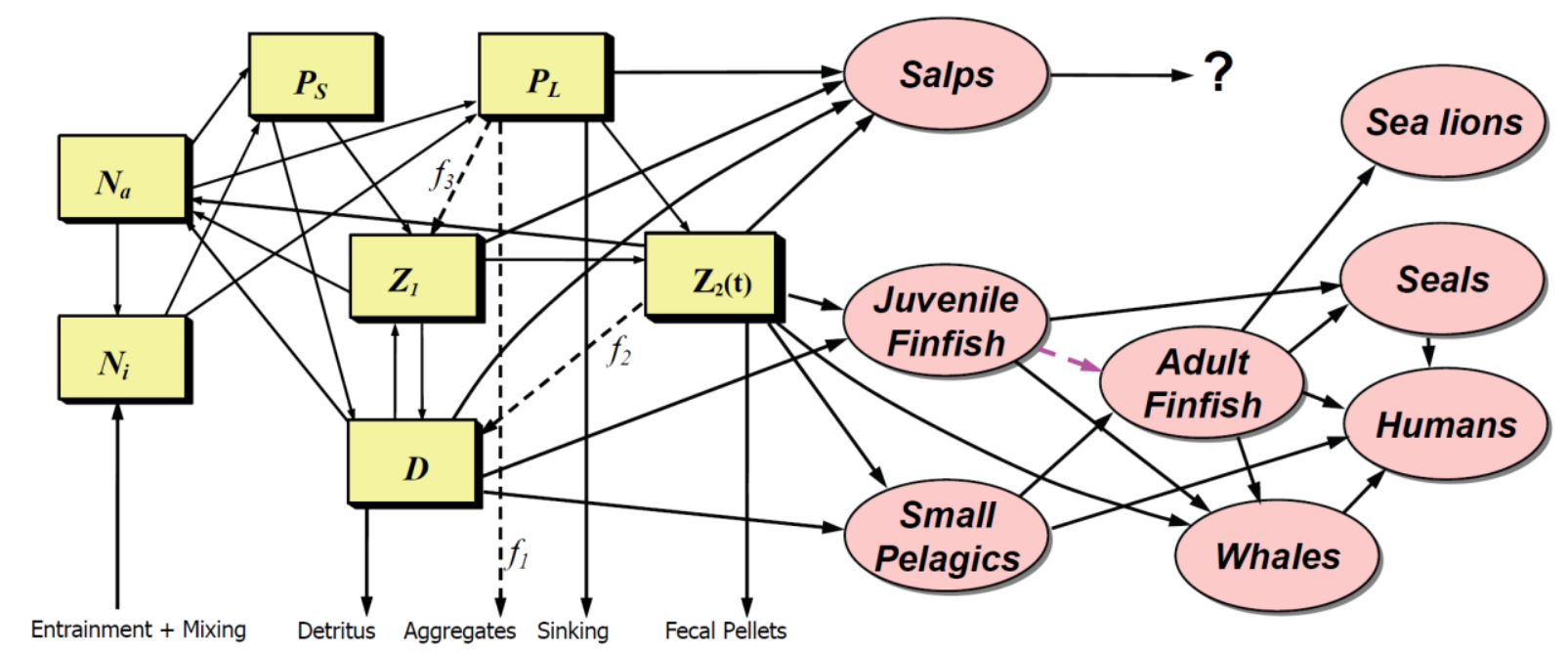

Figure 1. An 'End to End' food web view of the ocean ecosystem with mass flowing from a planktonic ecosystem

(left: yellow boxes) through to 'higher trophic levels' (right: pink boxes). The planktonic ecosystem consists of nutrients nitrate and ammonia $\boldsymbol{N}_{i}$ and $\boldsymbol{N}_{a}$, small and large phytoplankton $\boldsymbol{P}_{S}$ and $\boldsymbol{P}_{L}$, micro- and mesozooplankton $\boldsymbol{Z}_{\boldsymbol{1}}$ and $\boldsymbol{Z}_{2}$, and sinking organic particles $\boldsymbol{D}$.

This 'end to end' view of ocean ecosystems, "From physics to fish to us", spans more than 12 orders of magnitude, from individual organisms $<1 \mu \mathrm{m}\left(\equiv 10^{-6}\right.$ $\mathrm{m})$ in size to ocean basin ecosystems several thousand $\mathrm{km}\left(\equiv 10^{+6} \mathrm{~m}\right)$ across. The smaller organisms behave primarily as passive scalars of the flow, but starting with mesozooplankton $\boldsymbol{Z}_{2}$, which can migrate vertically several hundred metres in an hour, the larger organisms increasingly can overcome currents and turbulence primarily through swimming. Organisms not only exist in their physical environment, but they are affected, and affect, their biogeochemical environment (Gruber et al., this volume). In this 'front to back' view, an ocean ecosystem is envisioned as a set of parallel processors, each processing a different element. The base 'currency' of Fig. 1 is nitrogen N, but ocean ecosystems also participate in other elemental cycles: $\mathrm{C}, \mathrm{O}_{2}, \mathrm{~S}, \mathrm{Si}, \mathrm{P}, \mathrm{Fe}$, etc., usually transforming them between inorganic and organic, and dissolved and particulate phases. These interactions often are related via fixed ratios between elements, the so-called Redfield ratios, but much work over the last decade has been aimed at determining causal mechanisms for departures from these fixed ratios.

\subsection{Key Questions for Understanding Ecosystems}

If we are to understand ocean ecosystems well enough to improve our capabilities to predict their future behaviour, then we must develop observation systems aimed at answering the following questions:

- What species are present at any location and at what abundances?

- i.e. what is the 'texture' of life in the sea?
- Who eats who, how fast, when, and why?

- what rates are amenable to observation / inference?

- What are the scales of variability of marine life, how fast do things change, and what environmental factors regulate this change?

- What observational techniques and systems are available to inform us about the previous questions?

- What are key gaps in our observing abilities?

Observing what is there, how much, and at what rates are they changing due to sources and sink processes and due to advection and mixing in a sustained systematic fashion if we are to populate the compartments and arrows in Fig. 1 sufficiently to predict future behaviour of ocean ecosystems. In this paper we concentrate on the planktonic ecosystem, the rectangular compartments shaded yellow in Fig. 1.

\subsection{Key Uses of Sustained Ecosystem Observations}

Observing, modelling and managing ocean ecosystems fall naturally into two areas.

First, the open oceans beyond the territorial claims of any nation represent the largest 'global commons' for which all nations are collectively responsible for their management. The overall objectives for observing global ocean ecosystems are to detect interannual to multidecadal changes associated with global change from the background natural variability. Management objectives are to preserve ecosystem diversity by allowing sustainable use of marine resources. UNESCO (United Nations Educational Scientific and Cultural Organization) has overseen the design of 


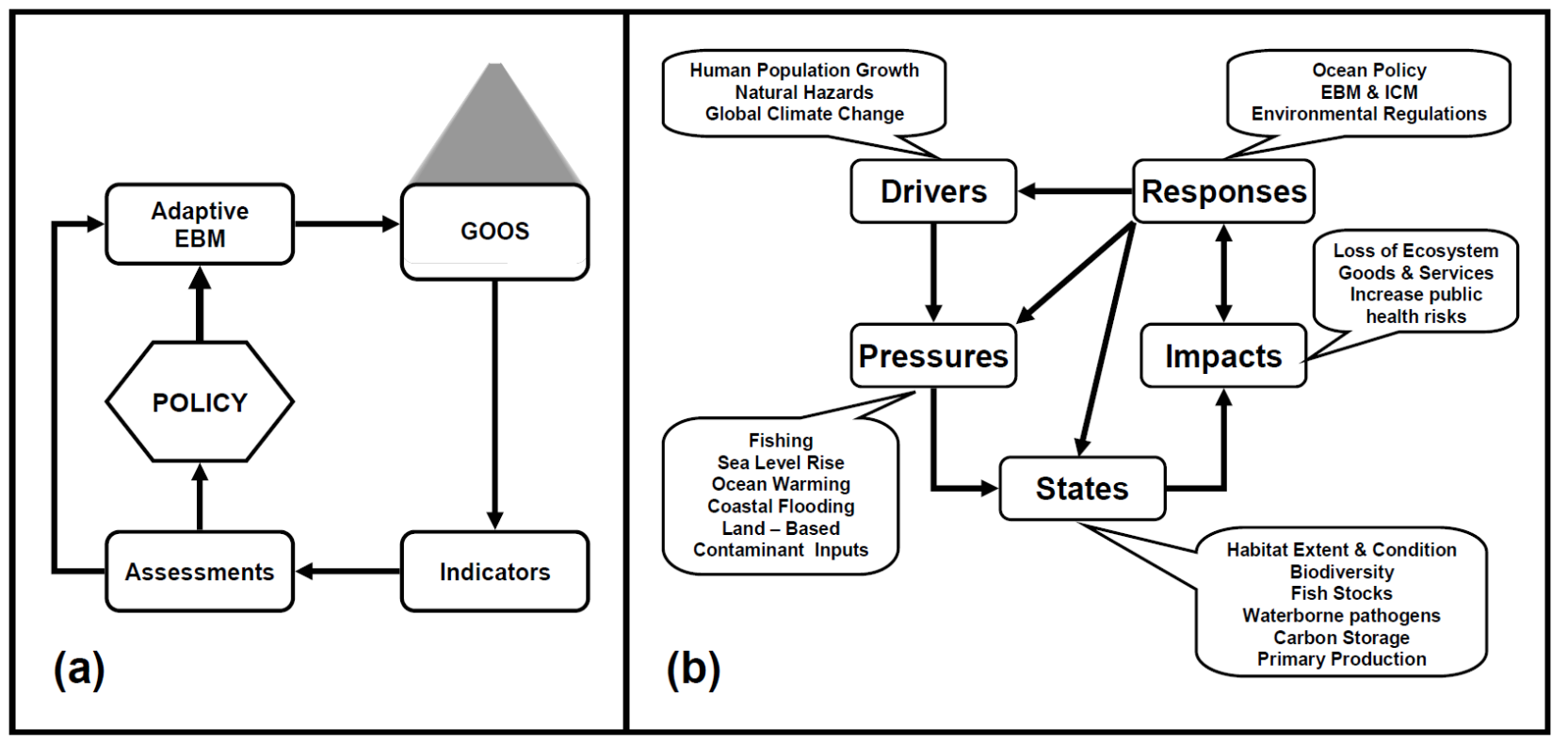

Figure 2. (a) Ecosystems are complex systems characterized by many variable properties and processes that cannot all be monitored in all places at all times. Thus, it is important to identify key ecological indicators that enable assessments needed to guide the evolution of ocean policies and adaptive, ecosystem-based management (EBM) practices for sustainable use of marine ecosystem goods and services. Coastal GOOS must evolve to provide data and information required to compute indicators routinely and continuously. (b) The driver-pressure-state-impact-response(DPSIR) model guides the identification of a set of indicators (with examples for each stage). As a group, the set of indicators will inform integrated ecosystem assessments on local, national, regional and global scales (EBM - ecosystem-based management; ICM - integrated coastal management). (Reprinted from [3].)

the observing system for open ocean ecosystems under the Global Ocean Observing System (GOOS) and the Global Climate Observing System (GCOS).

Second, the coastal oceans are managed by individual or small groups of adjacent nations again to permit sustainable uses while maintaining ecosystem diversity and environmental quality. Sustained observations must resolve shorter timescales and be spatially more dense in coastal regions than in the open ocean. A strategy for implementing sustained coastal observations has been developed by GOOS. Fig. 2, taken from [3] shows schematically (a) the flow of information from obtaining observations to ecosystembased management (EBM), and (b) the driver-pressurestate-impact-response (DPSIR) cycle that should inform ecosystem based management and integrated coastal management (ICM) on local, national, regional and global scales.

\section{SHIPBORNE OBSERVATIONS OF OCEAN ECOSYSTEMS AND THEIR 'TEXTURE'}

Obtaining samples for identifying the 'texture' and various rates of change of plankton requires taking water samples or capturing the organisms themselves. Rosette bottle samplers are used to obtain water for identifying and growing phytoplankton, usually after filtering the waters to isolate organisms in a given size range. Water samples are analyzed for nutrients, dissolved oxygen and other 'biogeochemical' properties, while precise times, depths, temperatures and salinities are obtained with electronic sensors when each bottle is tripped. In the open ocean where phytoplankton and other particulate organic matter is sparse, larger sampling bottles are used, of order $30 \mathrm{~L}$ in volume. For many uses, 'clean techniques' must used in obtaining the water samples, to avoid contamination. Estimates of phytoplankton 'biomass' concentration can be obtained by analyzing for chlorophyll or other pigments, or by isolating the amount of carbon and other elements in each sample. Individuals range in size from $\sim 1$ to $20 \mu \mathrm{m}$, so identification to species level still requires skilled individuals working with microscopes.

Any one location might contain hundreds of species of phytoplankton of various sizes, shapes, and ecological function. However, modellers have had some success at grouping phytoplankton species that fill similar ecological 'roles' into several 'Plankton Functional Groups', or PFTs [4] and [5]. In Fig. 3, we show single species examples of phytoplankton from four PFTs, considered to be the minimum number of 
phytoplankton PFTs to describe the most important ecological functions, of the phytoplankton, including their role in taking up and cycling carbon dioxide. Panel a shows an oceanic picoplankton. These small phytoplankton form the basis of the phytoplankton population in much of the ocean, and tend not to undergo spring blooms, so often referred to as the 'background' community. Panel b shows a nitrogenfixing diazotrophs. These small organisms can convert elemental nitrogen from the atmosphere to forms useable by other phytoplankton. Panel c shows a diatom. Diatoms are the 'bloom' organisms, they form their body parts from silica, and they tend to be the organisms that sink out of the upper ocean removing the carbon they contain from the surface ocean, i.e. they are the organisms that form the organic 'biological pump'. Finally, panel d shows a coccolithophorid, which uses calcium carbonate for the external coccoliths. By taking up charged carbonate ions they change the $p \mathrm{H}$ in such a way as to increase the partial pressure of carbon dioxide making it more difficult for atmospheric carbon dioxide to enter the ocean.

Towed nets are still used to capture zooplankton: mesh sizes of order $550 \mu \mathrm{m}$ are used, so animals larger than about $1 \mathrm{~mm}$ can be captured. Larger zooplankton can avoid smaller nets. For fish and larger zooplankton, nets with openings of several hundred square meters

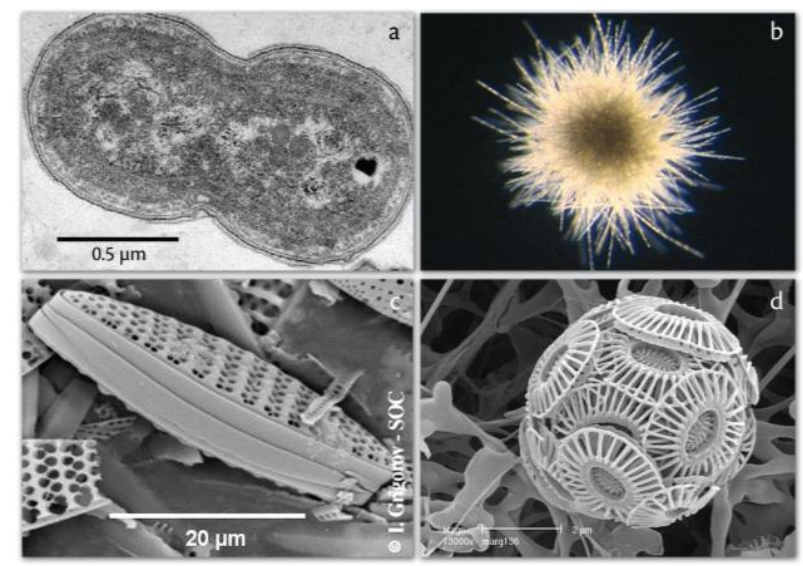

Figure 3. Oceanic photosynthetic microorganisms:

(a) Synechococcus, an abundant picoplankton species;

(b) colony of the cyanobacterium Trichodesmium (scale of image $4 \mathrm{~mm}$ ), a nitrogen fixing species; (c) the Southern Ocean diatom Fragilariopsis

kerguelensis, which has a thick, strong siliceous skeletal structure; (d) the coccolithophorid Emiliania

huxleyi, which forms intricate calcium carbonate plates (liths), changing alkalinity and surface $\mathrm{pCO}_{2}$. Top two photos courtesy of E. Webb and J. Waterbury, Woods Hole Oceanographic Institution, USA. Bottom two photos courtesy of National Centre for Oceanography, Southampton, UK. (Image reprinted from [4].) are sometimes used. Towed instrumented multiple opening and closing net systems are routinely used to obtain samples from a series of depth intervals.

Zooplankton are also diverse in terms of size, shape, and function, as illustrated in Fig. 4. The animals shown are mesozooplankton and two gelatinous species. Most microzooplankton and immature forms of mesozooplankton are smaller than $\sim 2 \mathrm{~mm}$, usually not visible to the naked eye, many of them overlapping in size the larger phytoplankton.

Over the last two decades, sediment traps, usually

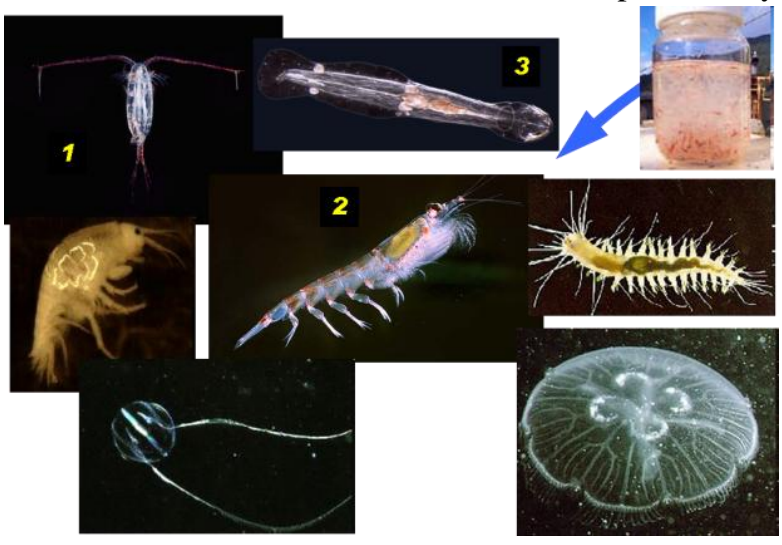

Figure 4. Images of various zooplankton, in the size range from $\sim 2 \mathrm{~mm}$ to tens of $\mathrm{cm}$. Sample jar in upper right shows contents collected after a standard net tow.

Numbered images are reproduced from Wikipedia under the GNU Free Documentation Licence, images 1 and 2 attributed to Uwe Kils. All other images available at [http://www.pac.dfo-mpo.gc.cal sci/osap/projects/plankton/].

moored at depths from several hundred to several thousand metres for periods of months to years, have been used extensively to capture organic particles that sink through the water column from the surface layer (the so-called 'biological pump'). Sediment traps have a series of sample tubes below a large funnel that are programmed to advance sequentially, each capturing particles for a set period of days to weeks, thereby building up a time series at each depth of the vertical sinking flux of particles. Samples from sediment traps comprise mainly fecal pellets, the solid waste products of zooplankton (Fig. 5). They also are requiring timeconsuming analysis under microscope as well as analytical analyses for the composition of major elements, e.g. carbon, nitrogen, phosphorus, etc. A major challenge must be to find ways of automating the identification and analysis of phytoplankton, zooplankton and sediment trap samples.

\section{EMERGING ECOSYSTEM OBSERVING SYSTEMS}

Following along the lines of [5], we will discuss briefly several key observing systems categorized as follows: 

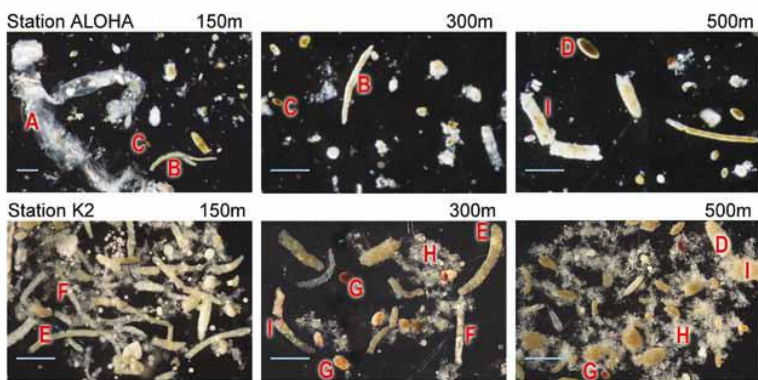

Figure 5. Changes in fecal pellet types with depth, from sediment trap samples from the subtropical Pacific (Hawaii Ocean Time-series, HOT, station ALOHA) and subarctic Pacific (Japanese time series site K2). Scale bar is $500 \mu \mathrm{m}$. (Reprinted from [6].)

- Optical plankton imaging and analysis systems

- Remote sensing - from space and with acoustics

- Time series stations - e.g. HOT, BATS, OSP

- Drifting buoys and gliders

- Repeat sections: CPR/SAHFOS, AMT

- Census of Marine Life (CoML) / Ocean Biogeographic Information System (OBIS)

These observing systems have all seen significant development over the last decade, and we will elaborate on some of them next.

\subsection{Optical Plankton Imaging and Analysis Systems}

It is clear from Figs. 3-5 that analyzing samples of individual phytoplankton, zooplankton, and sediment trap 'particles' to identify, count, and collectively weigh the individual organisms and particles is both time consuming and expensive, and cannot be completed in any time approaching 'real time'. The development of automated plankton recognition systems has developed along two lines: first, to speed up the analysis of samples collected with traditional nets, and second, to identify images of organisms collected in situ with video plankton recorders. Progress has been slow but steady as technology has developed; a number of possible systems now exist [7] and [8], but most of them still need considerable re-engineering to be suitable for long term systematic unattended observing systems.

Reference [7] summarizes the state of optical plankton imaging and analysis systems. Some general statements include: (i) Most planktonic organisms smaller than about $20 \mu \mathrm{m}$ (most phytoplankton and many microzooplankton) simple similar shapes not currently amenable to automatic recognition; (ii)
Analysis and software systems for plankton identification are less mature than the imaging hardware; (iii) Biofouling can degrade performance on long term deployments; (iv) Coastal regions present a particular challenge to discriminate the target particles against a high background of non-target particles; (v) Offshore regions present the challenge of observing a large enough volume (and broad depth of focus) in environments with a low density of particles; and (vi) New low-power, broad size-range digital holographic systems integrated into profiling floats show potential for remote sensing of plankton taxa over large areas of the ocean. Fig. 6 shows examples of the technology and images obtained with holographic systems.
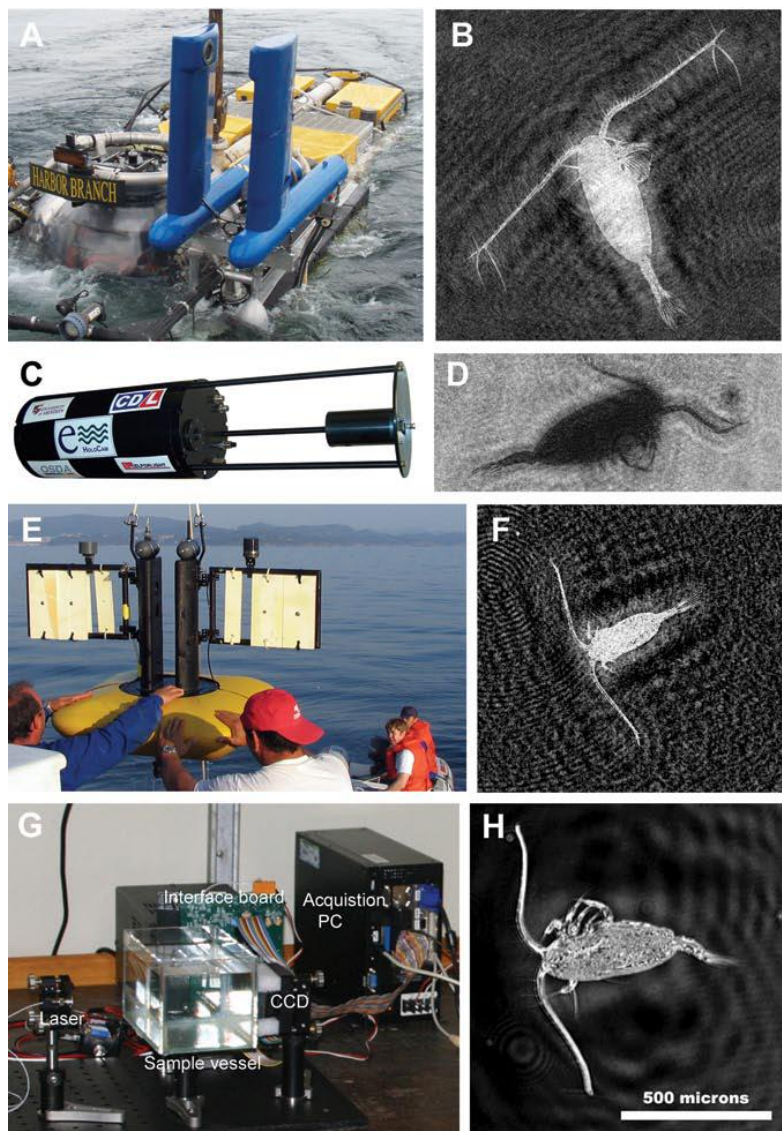

Figure 6. Holographic systems offer a means of imaging plankton over a broad range of sizes while preserving their spatial interrelationships. Examples of systems that are operational or under development (left) along with example images (right) of copepod zooplankton. (Reprinted from [8].)

\subsection{Remote Sensing - From Space and with Acoustics}

The advent of remote sensing of the oceans from satellite completely changed our views on ocean variability and dynamics. In the study of ocean ecosystems, satellite-borne ocean colour sensors 
remain the single technique by which we can observe ocean ecosystem properties synoptically at global scales. The continuous operation since September 1997 of the SeaWiFS (Sea-viewing Wide Field of View Sensor) sensor of ocean colour has allowed a 10-year record of changes in phytoplankton-related variables over the global ocean with minimal need for cross platform calibrations. Various missions for follow-on sensors are planned but are not all guaranteed [9] and [10]. In the last decade great progress has been made on building global networks to provide in situ calibrations for ocean colour sensors [11], and on estimating other properties besides chlorophyll pigment concentration as an indicator of near-surface phytoplankton biomass.

To estimate carbon-based primary production from space, we need estimates of chlorophyll pigment concentration, sea surface temperature, subsurface light intensity, and phytoplankton carbon-to-chlorophyll ratio. With the aid of many in situ and laboratory observations, algorithms have been developed to obtain primary production and related properties at the regional [12] and [13] and global scales [14] and [15]. Information on two PFTs is now available from satellite: coccolothophorid (Fig. 3d) blooms can be seen in the visible band because the calcium carbonate 'coccoliths' are white and exhibit high reflectivity. Well-documented differences in the light absorption spectrum for different PFTs have led to the development of an algorithm for estimating the percentage of diatoms (Fig. 3c) in a satellite colour image [13], [16] and [17], as illustrated in Fig. 7.

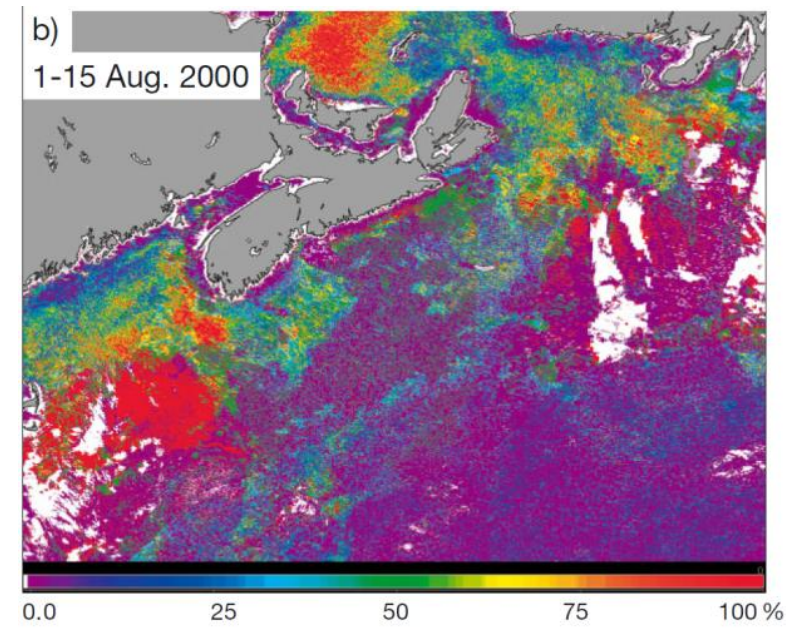

Figure 7. Satellite-derived probability that the phytoplankton population at a particular location is dominated by diatoms. (Reprinted from [17].)

Satellite borne ocean colour sensors have been and will continue to be a major component of any system to obtain systematic observations of ocean ecosystems. It must be stressed however that ocean colour sensors yield information only of phytoplankton and other 'particles', only in clear conditions and only of the near surface layer.

Active acoustics (transmitting sound signals and receiving the sound energy backscattered off targets) is a long-standing tool for distant/remote probing of animals from zooplankton to whales. Development of multi-frequency systems to obtain backscattered energy from different sizes of organisms/particles has been rapid in the last decade, partially enabled by the use of assimilating models of multiple levels of the ocean ecosystem [18].

\subsection{Time Series Stations - e.g. HOT, BATS, OSP}

Long term time series observations from fixed sites in the ocean provide the backbone of any observing system to resolve variability on interannual to century 'climate' time scales. Ocean Station Papa $\left(50^{\circ} \mathrm{N}\right.$, $145^{\circ} \mathrm{W}$ ) served as a weathership from the 1950 s until 1981, after which the Institute of Ocean Sciences has maintained $\sim 3$ research cruises a year to OSP. In 2007 a symposium was held to celebrate 50 years of oceanographic observations at OSP and at a series of stations along 'Line $\mathrm{P}$ ' between Vancouver Island and OSP [19]. Shorter duration but more intensive sampling programs emphasizing biogeochemical observations have been carried out near Bermuda (BATS) and north of Hawaii (HOT), both of which have already documented exciting variability on decadal scales.

Long term time series sites, because of the available background data characterizing the oceanography of the region, are ideal locations for more studies. Examples include the SOLAS-sponsored iron fertilization experiment at OSP in 2002 [20], and a year-long study at HOT documenting the dominance of two groups of archaeal microbes [21].

Currently, the small number of long term sites is being augmented by a combination [22] of additional deep ocean time series stations (OceanSITES (OCEAN Sustained Interdisciplinary Time series Environment observation System) [23] and coastal ocean observatories [24] such as NEPTUNE (North East Pacific Time-series Undersea Networked Experiments). Coastal ocean observatories will become important components of observing systems in support of Integrated Coastal Management.

\subsection{Drifting Buoys and Gliders}

The maturation of the Argo (Array for Real-time Geostrophic Oceanography) drifting buoy program [25] represents possibly the greatest success of the last decade for implementation of sustained ocean observing systems. With the exception of sensors for 
dissolved oxygen [26] and optical backscattering from particles [27], there is a lack of tested sensors for sustained observations of ocean ecosystems. The recent development of the Carbon Explorer profiling float [28] demonstrates the potential for obtaining vertical carbon flux estimates from a remote profiling drifter. A network of such profiling 'BIO-Argo' floats has been proposed to take advantage of the existing Argo float infrastructure [27].

\subsection{Repeat Sections: CPR/SAHFOS, AMT}

The value of repeat sections has been evident for over two decades due to the WOCE (WorId Ocean Circulation Experiment) and CLIVAR (Climate Variability and Predictability) programs. The value of combining repeat sections and broad coverage over many decades is best demonstrated by the Continuous Plankton Recorder survey in the North Atlantic, which has documented major 'regime' shifts [29]. The broad area coverage has allowed partitioning of the effects of local change versus multi-decadal northward movement of major species, presumably associated with global warming. Reference [30] reports on the expansion in progress to obtain global coverage. Reference [31] shows how samples from the Atlantic Meridional Transect repeat section are being used to determine the temporal variability in species diversity of two phytoplankton PFTs.

\subsection{Census of Marine Life (CoML) and OBIS}

The Census of Marine Life (CoML) is a network of scientific researchers from 80 countries, who are completing in 2010 a 10-year scientific project to assess comprehensively the diversity, distribution and abundance of life in the oceans [32]. The Ocean Biogeographic Information System [33] has been accepting data from the CoML and now contains 22.2 million records of 112,000 species of organisms from bacteria to whales, integrating observations from 744 individual data bases (as of 17 April 2010).

Figure 8 is derived from the OBIS data base. It shows the number of species in each $1^{\circ} \times 1^{\circ}$ 'pixel', normalized by the area of each 'pixel', but not by the number of records in each 'pixel'. White pixels represent areas where no observations have been taken, associated with the CoML. Figure 8 can be compared with a corresponding fig. in [33] from the same data showing the global distribution of Hurlbert's index of diversity, ES(50): the expected number of distinct species in a random sample of 50 observations of "microbes to whales" calculated on a grid of $5^{\circ} \times 5^{\circ}$.

Together the CoML and OBIS represent a massive effort at ocean observing and archiving that has little overlap with current systems for making sustained observations of the ocean. However, we feel that these large observing endeavours, along with the Continuous Plankton Recorder survey, must connect with each other if we are to develop an understanding of the dynamics of ocean ecosystems sufficient to forecast their future behaviour. Biodiversity and ocean physics (can) have strong scientific connections, as illustrated by [34], which reports on a modelling study where a high resolution $(18 \mathrm{~km})$ ocean general circulation model (OGCM) was seeded with 78 species of

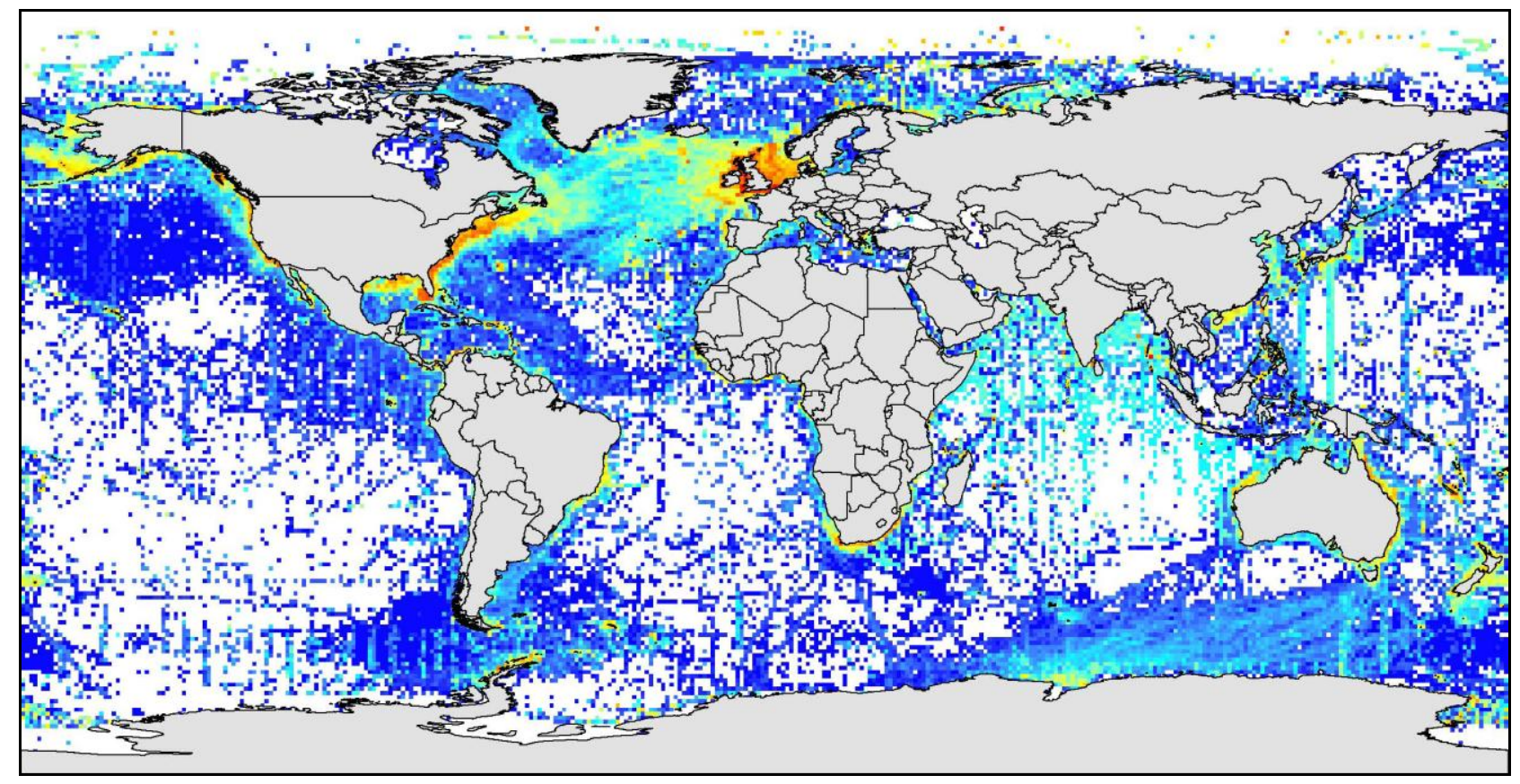

Figure 8. Number of species of phytoplankton in each $1^{\circ} \times 1^{\circ}$ 'pixel', normalized by the area of each 'pixel', but not by the number of records in each 'pixel'. From the more than 20 million records in the OBIS database [33]. 
phytoplankton, with physiological dependencies on nutrient, light, and temperature conditions randomly assigned from field and laboratory studies. The model included two types of zooplankton grazers. Some phytoplankton species went extinct, but after a number of simulated years the number of remaining species stabilized, with clear patterns at the basin scale. Building on this work, coupled OGCM models with longer 'end to end' ecosystem models should help to develop a dynamic understanding of the observed patterns in biodiversity [33].

\section{GAPS IN OBSERVING SYSTEMS FOR OCEAN ECOSYSTEMS}

This paper and several others describe the components of a future comprehensive observing system for ocean ecosystems. Based on the six components described in Sect. 3, we now briefly list gaps in existing systems, technological and organizational, that need to be addressed over the next decade, if we are to bring observing systems for ocean ecosystems to the level of maturity by the end of the next decade that we now see in existing systems for obtaining sustained and systematic observations of the physical state of the ocean.

- Ocean physics - Observations of vertical transport (mixing and advection) processes and rates are extremely important to estimate the vertical fluxes of dissolved (and sinking) substances, such as nutrients and dissolved organic matter, especially through the thermocline. Recent technological developments of neutrally-buoyant Lagrangian drifters [35] and [36] hold promise for limited scale measurements of vertical velocities. Despite a large ongoing effort in measuring and understanding rates of vertical mixing, obtaining sustained reliable estimates continues to challenge physical oceanographers.

- Engineering design - There exist many prototype systems for observing various properties of ocean ecosystems. Before such instrumentation can be incorporated into sustained observing systems, it must be re-engineered to be robust and reliable, and to require low power and low maintenance, all at an affordable cost. Different configurations will be required for deployment on different platforms such as fixed moorings, drifters and ships of opportunity.

\section{- Ocean ecology}

- Microzooplankton are tightly coupled to phytoplankton through grazing, yet our knowledge of their diversity and functioning is low because of limited abilities to observe them.

- Measurement of most rates (growth, death, eating, etc.) need to be continuous and/or automatic, especially "secondary production" by zooplankton.
- Observations of fish abundances and change are mostly obtained from fishing industry catch statistics, where they must be normalized to "catch per unit effort". Acoustics are a valuable methodology, but more tools are needed such as instrumented tags, both to track individual behaviour and movements and also to measure other environmental variables such as temperature, dissolved oxygen concentration, ambient light levels, etc., such as is planned for the Ocean Tracking Network [37]

\section{A STRATEGY FOR THE NEXT DECADE}

Two apparently contradictory statements summarize the current state of sustained observations of planktonic ecosystems. First, planktonic ecosystems, and to a lesser extent the oceans in general, are and will continue to be grossly undersampled, relative to the levels of observation we need in order to develop understanding of their dynamics sufficient for effective management of the oceans' resources and for robust forecasting of the future behaviour of the oceans and their ecosystems. Second, the amounts and diversity of data, both existing and to be collected over the next decade, seem overwhelming. With these two statements in mind, we present a set of core principles to help guide the development over the next decade of a strategy for a network of sustained observations of planktonic ecosystems, recognizing that coastal regions are both diverse and dynamic, thus requiring intensive observation systems that are probably going to be region-specific.

- Satellite remote sensing - Together with eulerian time series stations and an Argo-like system of profiling drifters, remotely-sensed imagery should form the core elements of observations of planktonic ecosystems. Satellite colour radiometry has nearly global coverage with kilometer-scale resolution, and can provide sub-seasonal to multidecadal coverage if inter-calibration between missions is adequate.

- Long term eulerian time series stations - These stations are essential for providing 'ground truthing' for satellite imagery, observations of water column profiles, and background data to support intensive fixed term process-based observational studies. As an example, the long term TOGA (Tropical Ocean Global Atmosphere) array of moorings in the tropical Pacific Ocean has underpinned our ability to monitor and forecast ENSO (El Niño Southern Oscillation) events.

- Long term Argo-like network of profiling drifters - Maintaining the Argo network is essential for optimal state estimation [38] of the oceans and for short term climate predictions [39]. If we are to develop robust predictions of future 
planktonic ecosystem behaviour, then we must also have robust predictions of the evolution of the physico-chemical ocean - because we are confronted with one complex system (the ocean ecosystem) embedded in another complex system (the physico-chemical ocean) both with numerous nonlinear interactions between components and each other. Adding only a dissolved oxygen (DO) sensor would greatly enhance our capability to monitor plankton production and carbon dioxide uptake, because DO anomalies in the surface layer represent an integrated estimate of net community production, and below the surface layer they represent an integrated estimate of net community respiration/remineralization.

- The Continuous Plankton Recorder Survey and other underway surveys - The CPRS, operating since 1931 mostly on ships of opportunity, represents a long standing data base of planktonic biomass and species assemblages, primarily for the North Atlantic [29]. Plans to extend the survey with a similar level of coverage to all oceans represent the best method to acquire broad coverage of zooplankton abundance and species information over the next decade [30]. Optical and acoustical plankton recorders [7] and [18] should also be added to underway ship surveys, especially from ships of opportunity.

- A catalogue of databases - Connecting observations by different groups. There exist a number of relatively independent observing systems for ocean ecosystems. Most of them do not readily fit the 'weather station' observing model. Rather, the different groups, such as SAHFOS (Sir Alister Hardy Foundation for Ocean Science), CoML, and Argo, have developed their own databases with their own scientific objectives in mind. These databases are individually wellmanaged, but are as diverse as the observations that they contain; realistically they cannot be combined into one uniform database. We need to ensure the maintenance of these databases into the future, and we need to develop a 'Catalogue of Databases' linking data stored by National Ocean Data Centres, CLIVAR, Argo, SAHFOS, Satellite imagery (e.g. the ocean colour groups IOCCG (International Ocean Colour Coordinating Group) and ChloroGIN (Chlorophyll Global Integrated Network)), FAO (Food and Agriculture Organization of the United Nations), CDIAC (Carbon Dioxide Information Analysis Center), OBIS/CoML, etc., such that they can be searched collectively by geographical area and by time.

- Coupled ocean ecosystem models and general circulation models - Optimal state estimation models of the ocean basically recognize uncertainties in both observations and in our understanding of ocean dynamics (as represented in the models) by taking a weighted average of observations and of model dynamics in making estimates of the current and future states of the ocean. Recognizing similar (or greater) limitations in both observations and models of ocean ecosystems, we must continue to develop models of ocean ecosystems embedded in ocean general circulation models. Such coupled models are the tool by which we integrate observations of the state of ocean ecosystems with models representing our understanding of how they work to provide predictions of their future behaviour.

The oceans and their ecosystems have great value to humans both emotionally and economically. Wise management of ocean resources requires sustained and substantial high quality observational systems. Much progress has been made and much remains to be done. We hope that this paper contributes to the task.

\section{REFERENCES}

1. Gunn, J., Rogers, A. and Urban, E., (2010). "Observation of Ocean Biology on a Global Scale: Implementing BioGOOS?" in these proceedings (Vol. 1), doi:10.5270/OceanObs09.pp.20.

2. Claustre, H. \& Co-Authors (2010). "Bio-Optical Profiling Floats as New Observational Tools for Biogeochemical and Ecosystem Studies: Potential Synergies with Ocean Color Remote Sensing." in these proceedings (Vol. 2), doi:10.5270/OceanObs09.cwp.17.

3 Malone, T. \& Co-Authors (2010). "Building a Global System of Systems for the Coastal Ocean: A Strategic Action Plan for Implementing the Coastal Module of GOOS" in these proceedings (Vol. 2), doi:10.5270/OceanObs09.cwp.59.

4. Rothstein, L., Abbott, M., Chassignet, E., Cullen, J.J., Denman, K., Doney, S., Ducklow, H., Fennel, K., Follows, M., Haidvogel, D., Hofmann, E., Karl, D., Kindle, J. Lima, I. Maltrud, M. McClain, C., McGillicuddy, D., Olascoaga, J., Spitz, Y., Wiggert, J. \& Yoder, J. (2006). Modeling Ocean Ecosystems: The PARADIGM Program, Oceanography, 19-1, 22-51.

5. Le Quéré, C. \& Co-Authors (2010). "Observational Needs of Dynamic Green Ocean Models" in these proceedings (Vol. 2), doi:10.5270/OceanObs09.cwp.56.

6. IGBP Global Change Newsletter 73, April 2009, p.13.

7. Sieracki, M. \& Co-Authors (2010). "Optical Plankton Imaging and Analysis Systems for Ocean Observation" in these proceedings (Vol. 2), doi:10.5270/OceanObs09.cwp.81.

8. Benfield., M.C., Grosjean, P., Culverhouse, P., Irigoien, X., Sieracki, M.E., Lopez-Urrutia, A., Dam, H.G., Hu, Q., Davis, C.S., Hansen, A., Pilskaln, C.H., Riseman, E., Schultz, H., Utgoff, P.E. \& Gorsky, G. (2007). RAPID: Research on Automated Plankton Identification. Oceanography 20, 12-26. 
9. Yoder, J. (2010). "Ocean Colour Radiometry: Early Successes and a Look Towards the Future" in these proceedings (Vol. 1), doi:10.5270/OceanObs09.pp.43.

10. Yoder, J., Dowell, M., Hoepffner, N., Murakami, H. and Stuart, V., (2010). "The Ocean Colour Radiance Virtual Constellation (OCR-VC)." in these proceedings (Vol. 2), doi:10.5270/OceanObs09.cwp.96.

11. Sathyendranath, S. \& Co-Authors (2010). "ChloroGIN: Use of Satellite and In Situ Data in Support of Ecosystem-Based Management of Marine Resources" in these proceedings (Vol. 2), doi:10.5270/OceanObs09.cwp.75.

12. Sathyendranath, S., Stuart, V., Nair, A., Oka, K., Nakane, T., Bouman, H., Forget, M.H., Maass, H. \& Platt, T. (2009). Carbon-to-chlorophyll ratio and growth rate of phytoplankton in the sea. Marine Ecology-Progress Series 383, 73-84.

13. Platt, T., Sathyendranath, S., Forget, M.H., White, G.N., Caverhill, C., Bouman, H., Devred, E. \& Son, S. (2008). Operational estimation of primary production at large geographical scales. Remote Sensing of Environment 112, 3437-3448.

14. Behrenfeld, M.J., Boss, E., Siegel, D.A. \& Shea, D.M. (2005). Carbon-based ocean productivity and phytoplankton physiology from space. Global Biogeochemical Cycles, 19, GB1006, doi:10.1029/2004GB002299.

15. Behrenfeld, M.J., O'Malley, R.T., Siegel, D.A., McClain, C.R., Sarmiento, J.L., Feldman, G.C., Milligan, A.J., Falkowski, P.G., Letelier, R.M. \& Boss, E.S. (2006). Climate-driven trends in contemporary ocean productivity. Nature $444,752-755$.

16. Ciotti, A.M., Cullen, J.J. \& Lewis, M.R. (2002). Assessment of the relationships between dominant cell size in natural phytoplankton communities and the spectral shape of the absorption coefficient. Limnology and Oceanography, 47, 404-417.

17. Sathyendranath, S., Watts, L., Devred, EM, Platt, T., Caverhill, C. \& Maass, H. (2004). Discrimination of diatoms from other phytoplankton using ocean-colour data. Marine Ecology-Progress Series 272, 59-68.

18. Handegard, N. \& Co-Authors (2010). "Toward a Global Ocean Ecosystem Mid-Trophic Automatic Acoustic Sampler (MAAS)" in these proceedings (Vol. 2), doi:10.5270/OceanObs09.cwp.40.

19. Peña, M.A. \& Bograd, S.J. (2007). Time series of the northeast Pacific. Progress in Oceanography 75, 115117.

20. Harrison, P.J. (2006). SERIES (subarctic ecosystem response to iron enrichment study): A Canadian-Japanese contribution to our understanding of the iron-oceanclimate connection - Preface. Deep-Sea Research II 53, 2006-2011.

21. Karner, M.B., DeLong, E.F. \& Karl, D.M. (2001). Archaeal dominance in the mesopelagic zone of the
Pacific Ocean. Nature 409, 507-510.

22. Lampitt, R. \& Co-Authors (2010). "In Situ Sustained Eulerian Observatories" in these proceedings (Vol. 1), doi:10.5270/OceanObs09.pp.27.

23. Send, U. \& Co-Authors (2010). "OceanSITES" in these proceedings (Vol. 2), doi:10.5270/OceanObs09.cwp.79.

24. Favali, P. \& Co-Authors (2010). "Seafloor Observatory Science" in these proceedings (Vol. 2), doi:10.5270/OceanObs09.cwp.28.

25. Freeland, H. \& Co-Authors (2010)."Argo - A Decade of Progress" in these proceedings (Vol. 2), doi:10.5270/OceanObs09.cwp.32.

26. Gruber, N. \& Co-Authors (2010). "Adding Oxygen to Argo: Developing a Global In Situ Observatory for Ocean Deoxygenation and Biogeochemistry" in these proceedings (Vol. 2), doi:10.5270/OceanObs09.cwp.39.

27. Claustre, H. \& Co-Authors (2010). "Bio-Optical Profiling Floats as New Observational Tools for Biogeochemical and Ecosystem Studies: Potential Synergies with Ocean Color Remote Sensing." in these proceedings (Vol. 2), doi:10.5270/OceanObs09.cwp.17.

28. Bishop, J. \& Wood, T.J. (2009). Year-round observations of carbon biomass and flux variability in the Southern Ocean. Global Biogeochemical Cycles 23, GB2019, doi:10.1029/2008GB003206.

29. Burkill, P. and Reid, P., (2010). "Plankton Biodiversity of the North Atlantic: Changing Patterns Revealed by the Continuous Plankton Recorder Survey" in these proceedings (Vol. 1), doi:10.5270/OceanObs09.pp.09.

30. Reid, P. \& Co-Authors (2010). "A Global Continuous Plankton Recorder Programme" in these proceedings (Vol. 2), doi:10.5270/OceanObs09.cwp.73.

31. Cermeño, P., Dutkiewicz, S., Harris, R.P., Follows, M., Schofield, O. \& Falkowski, P.G. (2008). The role of nutricline depth in regulating the ocean carbon cycle. US Proceedings of the National Academy of Sciences 105:20344-20349.

32. O'Dor, R. \& Co-Authors (2010). "Bringing Life to Ocean Observation" in these proceedings (Vol. 1), doi:10.5270/OceanObs09.pp.29, and www.coml.org/

33. Vanden Berghe, E., Halpin, P., Lang da Silveira, F., Stocks, K. and Grassle, F., (2010). "Integrating Biological Data into Ocean Observing Systems: The Future Role of OBIS" in these proceedings (Vol. 2), doi:10.5270/OceanObs09.cwp.91.

34. Follows, M.J., Dutkiewicz, S., Grant, S. \& Chisholm, S.W. (2007). Emergent biogeography of microbial communities in a model ocean. Science 315, 1843-1846.

35. D'Asaro, E. A. (2003). Performance of autonomous Lagrangian floats. Journal of Atmospheric and Oceanic Technology 20, 896-911.

36. Barth, J. A., D. Hebert, et al. (2004). Direct observations of along-isopycnal upwelling and diapycnal velocity at a shelfbreak front'. Journal of Physical Oceanography 34, 543-565. 
37. O'Dor, R. \& Co-Authors (2010). "The Ocean Tracking Network" in these proceedings (Vol. 2),

doi:10.5270/OceanObs09.cwp.66

38. Heimbach, P. \& Co-Authors (2010). "Observational Requirements for Global-Scale Ocean Climate Analysis: Lessons from Ocean State Estimation" in these proceedings (Vol. 2), doi:10.5270/OceanObs09.cwp.42.

39. Hurrell, J. \& Co-Authors (2010). "Decadal Climate Variability, Predictability and Prediction: Opportunities and Challenges" in these proceedings (Vol. 1), doi:10.5270/OceanObs09.pp.23. 